\title{
Using The Major Field Test-Business As An Assessment Tool And Impetus For Program Improvement: Fifteen Years Of Experience At Virginia Military Institute
}

H. Francis Bush, (Email: bushhf@vmi.edu), Virginia Military Institute Floyd H. Duncan, (Email: duncanfh@vmi.edu), Virginia Military Institute Edwin A. Sexton, (Email: sextone@byui.edu), Brigham Young University-Idaho Clifford T. West, (Email: westct@vmi.edu), Virginia Military Institute

\begin{abstract}
We examine the history of VMI's use of the Major Field Test as an assessment tool for its Department of Economics and Business. Further, we chronicle how the information gathered from a decade and a half of use has shaped the curriculum, faculty composition and policies within the Department. There is evidence that the policies surrounding how and when the Major Field Test is administered influences student performance on the test and that it can be a valuable component of a comprehensive assessment program.
\end{abstract}

\section{LITERATURE REVIEW: PROGRAM ASSESSMENT \& MAJOR FIELD TESTS}

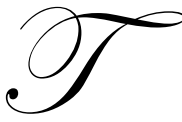

he use of the Educational Testing Service's (ETS) Major Field Test in Business (MFTB) as an assessment tool has gained broader acceptance over time, as evidenced by the increasing number of students taking the exam and schools included in the reported results from year to year. No doubt the strict requirements by accrediting bodies for business schools to document assessment plans and continuous improvement has led more and more business programs to use the MFTB as a measure of core knowledge. While many other types of assessment can also be successfully employed (Payne et al. (2002)), the MFTB has been found by various authors to provide an excellent measure of student learning outcomes that combines reliability, validity and a quick way for institutions to establish a baseline and benchmark against national norms (Mirchandani et al. (2001)).

Martell (2007) discussed assessment practices at collegiate business schools in light of AACSB's 2003 changes in accreditation standards. In particular, a much greater proportion of accreditation criteria and sub-criteria (i.e., 33\% vs. 10\%) became related to assurance of learning. Every degree program (not majors within a program) must define learning goals and demonstrate measurable progress toward their accomplishment, in terms of observable student behaviors. Faculty members are expected to be directly involved in these efforts, including changes and improvements as necessary and appropriate.

Martell reported the results of a 2006 survey of business school deans on assurance of learning practices. "Survey results indicate frequent use of direct assessment methods in 2006 including (a) written assignments evaluated with a rubric $(70 \%)$, (b) oral presentations with a rubric $(65 \%)$, (c) course-imbedded assessments (e.g., written, oral and case assignments) with a rubric (58\%), (d) cases evaluated with a rubric (46\%), (e) Educational Testing Service's Major Field Tests (46\%), and (f) systematic evaluation of teamwork (42\%) are all popular direct assessments. Survey (of graduates, employers, etc.) is considered an indirect assurance of learning measure. Since 
2004, its use as a measure is still high, but reduced." (pg. 191) Further, she reported that assurance of learning activities are better funded than in the past and that deans' greatest concern is closing the loop...using assurance of learning results to initiate curricular and pedagogical improvements. The bottom line is that, for schools seeking accreditation or re-accreditation, improvements via assurance of learning practices are no longer optional but mandatory under current AACSB guidelines.

Pringle and Mitri (2007) reported the results of a survey of assessment practices at 138 AACSB-accredited business programs, in the wake of the 2003 assurance of learning mandate. They found evidence of schools moving toward compliance but in a meandering, trial and error manner. They also discussed the continuing use and value of indirect assessment measures, such as employer and alumni surveys. While no longer solely sufficient, they can yield valuable insights that help to explain the results of direct assessments (e.g., inconsistencies in multi-instructor courses). They concluded that faculty will become vigorous supporters of assurance of learning assessments when they can see meaningful improvements in curriculum, pedagogy and student performance as a result.

Black and Duhon (2003) discussed the use of standardized tests in business programs to assess student achievement and improve those programs. In particular, they examined the MFTB, with regard to its reliability and validity (content and criterion). The MFTB measures students' mastery of concepts, principles and knowledge in economics, accounting, management, marketing, finance, quantitative business analysis, international business and legal and social environment. ETS itself provides statistical evidence that the MFTB demonstrates internal reliability (i.e., the Kuder-Richardson reliability coefficient). ETS utilizes faculty and other experts to insure test questions are appropriately representative of a field of study. However, Black and Duhon note that content validity may be an issue school-by-school, because the MFTB only samples topics within a given field. They followed the lead of Allen and Bycio (1997) and Mirchandani et al. (2001) in assessing the criterion validity of the MFTB. As had the earlier studies, they found MFTB scores to be associated with business GPA, ACT and SAT scores and business major (i.e., non-quantitative majors scored lower).

Black and Duhon point out that standardized test scores can be used for program and student learning outcomes and for continuous improvement at both levels. Program comparisons and unit performance reviews can lead to curriculum and pedagogy changes as well as resource reallocations. Student scores may be tied to course and graduation requirements, lead to identifying at-risk students or indicate the need for other proficiency tests. (pg. 95, Table 4) Further, they explain that standardized tests are unlikely to yield valuable results, if schools approach them haphazardly or unenthusiastically.

Bycio and Allen (2007) revisited the topic of their 1997 study, examining the correlates of MFTB scores. They looked at undergraduate GPA, business GPA, business major GPA, SAT scores and an indicator of student motivation in taking the test. They found MFTB score and business GPA were strongly and significantly related. However, MFTB was also strongly related to SAT-Verbal and undergraduate GPA, as measures of overall intelligence and test-taking capabilities, which muddies the waters somewhat, as DeMong et al. (1994) also pointed out. Bycio and Allen did not find significant differences in scores for major and gender; although, accounting and finance students tended to score higher on average. Interestingly, they also found that student motivation in taking the MFTB was significantly related to test performance, even when SAT scores and business GPA were accounting for in their model.

This opens the door to a discussion of contextual and administration issues surrounding the use of the MFTB as an assessment tool. Because MFTB scores may be significantly influenced by the quantitative component of a curriculum, by overall intelligence and test-taking ability, and by individual motivation, test results should be interpreted carefully. It would be reasonable to expect, for instance, the institutional scores at highly selective schools to be higher than for those schools less so. Also, faculty administering the MFTB carelessly and students taking it without enthusiasm could very well interact to yield lower individual and institutional results. 


\section{BACKGROUND INFORMATION ON VMI AND THE DEPARTMENT OF ECONOMICS AND BUSINESS}

Founded in 1839, Virginia Military Institute (VMI) is the oldest state-sponsored military college in the nation. VMI is a wholly undergraduate, co-educational college of 1375 students, offering degrees in engineering, science, and the liberal arts. All cadets live in a four story barracks and must adhere to a strict military regimen, similar to the federal service academies.

In 1964, the Department of Economics was separated from the Department of History, with the first bachelor degrees in economics being awarded in 1968. The economics degree was a popular major, primarily because cadets saw economics as a proxy for business. In fact, the early curriculum featured two required accounting courses listed under an economics (i.e., EC) label, as well as a corporate finance elective similarly identified. In 1984, in response to external pressure from alumni and from the school's governing body, the department introduced a management concentration that added courses in management and marketing and featured electives from engineering and psychology. Reliance on adjunct faculty and a general lack of resources created scheduling and quality control problems, which largely precluded students from successfully completing the concentration. After three unproductive years, a commitment was made by the school's administration to support the program and to expand courses offerings in business

In 1987, the department was transformed into the Department of Economics and Business (EC-BU) and introduced a new curriculum that gave business a nearly equal footing with economics. The EC-BU Department remained part of VMI's Liberal Arts Division, with language, English and history as prominent aspects of its curriculum. The program was, in effect, a double major, providing generalist degrees in each area. (Until a concentration in Financial Management was added in 1999, no specializations were offered.) Thus, with sufficient resources allocated in support the new department, a Bachelor of Arts in Economics and Business was awarded for the first time in 1990.

\section{VMI'S HISTORY WITH THE MFTB}

In an effort to assess the effectiveness of its new curriculum, the department adopted an assessment plan that featured the administration of the MFTB. The results from the first two years were disappointing. Students were required to take the test during what would otherwise be free time; and, with no connection to course completion or graduation, incentives and consequences were sorely lacking.

For the Class of 1993, the EC-BU Department introduced a Business Policy capstone course, and the MFTB became a course requirement, with the intention of giving students motivation to excel on the test. The department petitioned and received approval from VMI's Academic Board to administer the MFTB as a surrogate for a Business Policy final exam and have it count as $20 \%$ of the course grade. This was highly unusual, because students were being tested on material not explicitly covered in that course. The Academic Board approved because of the MFTB's role in overall program assessment. VMI's percentile scores by year and by discipline are recorded in Table I. Figure I provides a graphical representation of VMI's institutional percentiles. Individual discipline scores are further illustrated in Appendix A. After just a few years, the results of the MFTB revealed significant variability and some weaknesses in the Economics and Business program at VMI.

Those were not the only problems encountered. Due in large part to a de-valuing of the MFTB by faculty and students alike, results for the class of 2002 were VMI's lowest on record. Test administration and oversight had been inconsistent year-to-year, and 2002's results reflected many students' lackadaisical attitudes in taking the test. In our opinion, the results from 2002 illustrate the sensitivity of departmental-level scores to the relative emphasis on the MFTB in the degree program and policies surrounding its administration. Measures taken by the department to guard against future poor performance will be discussed later. 
Table I

\begin{tabular}{|c|c|c|c|c|c|c|c|c|c|c|c|c|c|c|c|c|}
\hline \multicolumn{10}{|c|}{ VMI PERCENTILE SCORES BY AREA 193-2007 } \\
\hline Areas & $\mathbf{9 3}$ & $\mathbf{9 4}$ & $\mathbf{9 5}$ & $\mathbf{9 6}$ & $\mathbf{9 7}$ & $\mathbf{9 8}$ & $\mathbf{9 9}$ & $\mathbf{0 0}$ & $\mathbf{0 1}$ & $\mathbf{0 2}$ & $\mathbf{0 3}$ & $\mathbf{0 4}$ & $\mathbf{0 5}$ & $\mathbf{0 6}$ & $\mathbf{0 7}$ & Average \\
\hline Accounting & 56 & 66 & 38 & 53 & 56 & 71 & 39 & 30 & 52 & 25 & 57 & 62 & 63 & 24 & 87 & $\mathbf{5 2}$ \\
\hline Economics & 99 & 99 & 94 & 99 & 98 & 98 & 98 & 99 & 99 & 97 & 99 & 99 & 98 & 98 & 98 & $\mathbf{9 8}$ \\
\hline Management & 73 & 60 & 47 & 63 & 46 & 82 & 59 & 54 & 85 & 23 & 91 & 80 & 92 & 92 & 85 & $\mathbf{6 9}$ \\
\hline Quantitative & 94 & 90 & 91 & 92 & 90 & 84 & 78 & 76 & 96 & 48 & 95 & 88 & 87 & 95 & 70 & $\mathbf{8 5}$ \\
\hline Finance & 96 & 94 & 41 & 79 & 81 & 76 & 70 & 71 & 87 & 50 & 91 & 84 & 92 & 83 & 99 & $\mathbf{8 0}$ \\
\hline Marketing & 75 & 78 & 75 & 77 & 53 & 85 & 59 & 71 & 82 & 36 & 79 & 98 & 86 & 95 & 97 & $\mathbf{7 6}$ \\
\hline Legal/Social & - & 76 & 52 & 96 & 65 & 71 & 50 & 82 & 54 & 28 & 89 & 54 & 85 & 55 & 51 & $\mathbf{6 5}$ \\
\hline International & - & 86 & 80 & 99 & 96 & 88 & 79 & 74 & 96 & 85 & 99 & 99 & 86 & 95 & 99 & $\mathbf{9 0}$ \\
\hline $\begin{array}{c}\text { \%tile all } \\
\text { institutions }\end{array}$ & 95 & 92 & 71 & 93 & 85 & 87 & 74 & 80 & 92 & 48 & 93 & 93 & 94 & 95 & 95 & $\mathbf{8 6}$ \\
\hline
\end{tabular}

Figure I

\section{VMI Ranking}

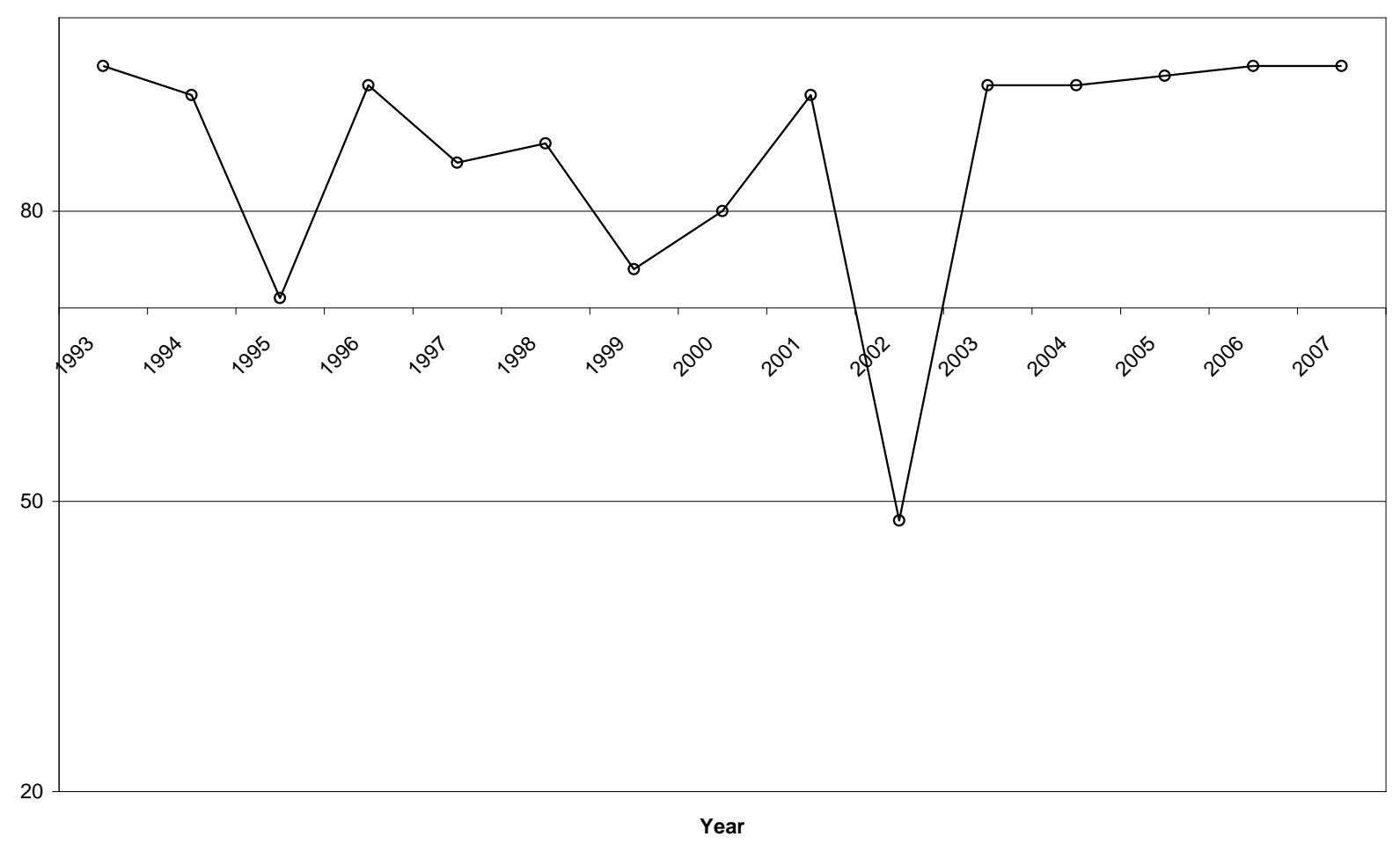

The EC-BU Department became a candidate for AACSB accreditation in 2004. Until then, the MFTB was the only formal indicator of departmental performance. In the interim, we have added additional perspectives and elements into a comprehensive, multi-dimensional plan. Broadly, the department has divided its assessment tools and procedures into direct and indirect components, as discussed by Martell (2007). The MFTB is considered a direct measure of discipline-based knowledge and skills, along with course-imbedded objectives and measurements. The MFTB provides a macro perspective, yielding longitudinal data on aggregate performance. Course-level assessment provides a micro perspective, often topic-by-topic. Additional direct measurement is (or will soon be) made of written and oral skills, technological competency, leadership experience, critical thinking and ethical 
reasoning. Annually, the department surveys its graduating seniors to assess their perceived proficiency with regard to the eight functional areas scored by the MFTB and the other direct skills and competencies mentioned above. In addition, EC-BU alumni and employers are regularly surveyed, as to the professional importance of the same functional areas, skills and competencies. Together, senior, alumni and employer results constitute indirect evidence on program performance. By 2009-10, all pilot tests will have been performed, and all aspects of the comprehensive plan will be in place.

With the onset of the department's AACSB accreditation efforts, the use and significance of the MFTB naturally and necessarily evolved. In the present context, the MFTB serves the critical role of a continuity measure. In fact, the department's assessment plan is so new that it is one of only a handful of measures for which multiple years of data exist (i.e., MFTB, senior survey, written and oral communication rubrics). In the past, the MFTB served as the "red flag" for problems in specific disciplines or the overall curriculum. Going forward, courseimbedded assessments should fill that role, and the MFTB should provide evidence of implementation success, with regard to accreditation-generated change.

\section{THE MFTB AS AN IMPETUS FOR PROGRAM IMPROVEMENT (I.E., CLOSING THE LOOP)}

In the early years, the MFTB provided a rationale for curriculum, faculty and policy changes, as opposed to reliance on assumptions or subjective comparisons with peer institutions. More recently, changes have focused on fulfilling AACSB guidelines and standards. But, regardless of the impetus, the MFTB continues to help us ascertain the necessity and effectiveness of changes within the department.

\section{Curriculum Changes}

As seen in Table 1, consistently low scores in accounting were a concern, almost from the outset. The faculty suspected they were the result of only one required semester of financial accounting, while the national norm for undergraduate business degrees was a two-semester financial accounting and managerial accounting sequence. In addition, inconsistent MFTB scores in legal and social environment and the broad management area led us to believe that required courses in business law, operations and management information systems were needed.

A managerial accounting course was added to the degree program in 2004, followed by law and operations in 2005 and management information systems in 2006. Although the MFTB had identified these problems years earlier, it was the pursuit of AACSB accreditation which provided the catalyst for the VMI administration to approve the course additions and to allocate the resources for full-time, terminally-qualified faculty to teach them.

\section{Faculty Changes}

During the 1992-1993 academic year, the faculty of VMI's EC-BU Department consisted of five Ph.D. economists (one of which taught in the area of finance), a temporary faculty member with a Masters degree in accounting, and a long-term, non-tenure eligible faculty member with an MBA. For the five years prior to 2002-03, the department regularly employed adjuncts to teach required and elective business courses. In fact, Table II clearly indicates the disparity in terminally qualified, full-time faculty coverage between the economics and business sides of the major.

As mentioned above, MFTB scores across the years had pointed to significant, enduring problems in six of the eight areas tested. Specifically, it was felt that a reliance on adjunct or non-terminally qualified business faculty in marketing, management and legal/social contributed to significant variability in cadet scores in these areas. The year-to-year superior performance of cadets in economics and quantitative analysis was attributed to the genesis of the major and the fact that these courses were routinely taught by terminally qualified, permanent faculty.

Since 1993, the department has hired its first Ph.D.'s in accounting, management, marketing, financial economics, operations management, and management information systems and its first J.D. to teach in the area of legal and social environment. The change in the composition of the faculty and the significant allocation of 
resources to the business side of the curriculum was directly related, prior to 2004, to improving the program and more recently to the department's pursuit of AACSB accreditation.

The importance of not assigning adjunct faculty lacking terminal qualifications to important, required courses was demonstrated, once again, for the class of 2006. As can be seen from the scores in Table I, the class of 2006 scored in the $95^{\text {th }}$ percentile, the highest overall ranking since the class of 1993 . This impressive showing was somewhat overshadowed by a disappointing $24^{\text {th }}$ percentile ranking in accounting. The sole accounting course for this class was taught by an adjunct faculty, while the permanent member was on sabbatical leave. The grade distribution for the students in that course was almost all A's, and the adjunct's student evaluations were high and glowing. Not surprisingly, the score for accounting was in the 85th percentile for the class of 2007, accompanying an overall score once again in the $95^{\text {th }}$ percentile. That nearly 50 percent of these students had also taken managerial accounting as a business elective further explains these results. Ironically, the average accounting grade awarded by the permanent instructor has been the minimum acceptable C. And, approximately 30 percent of all students must retake the course to receive a $\mathrm{C}$ or better.

\section{Policy Changes}

Alterations to department operating policies have been among the most lasting and important impacts of the MFTB. Adding required courses to the curriculum and tenure-eligible faculty requires outside approval and resources. Yet, VMI guidelines allow us considerable leeway in our day-to-day operations.

What is now obvious in the midst of seeking AACSB accreditation was not the case ten or fifteen years ago. Erratic performance on the MFTB convinced the department that assessment is important and should be taken seriously. In addition, we came to understand that assessment must be regular and consistent. Consistency removes other explanations for test results.

MFTB scores have become a "benchmark" for departmental performance with the VMI administration. In the annual report, the department chair defines minimum acceptable and desired percentiles for the up-coming year and details current outcomes. Significant deficiencies must be explained and become "action items" for the next evaluation cycle.

Table II: (EC-BU Faculty Composition)

\begin{tabular}{|c|c|c|}
\hline Academic Year & Economics & Business \\
\hline $92-93$ & $6 \mathrm{FT} / \mathrm{TQ}$ & 1 FT/NTQ; 2 PT/NTQ \\
\hline $93-94$ & $6 \mathrm{FT} / \mathrm{TQ}$ & 1 FT/TQ; 1 FT/NTQ; 1 PT/NTQ \\
\hline $94-95$ & $6 \mathrm{FT} / \mathrm{TQ}$ & 2 FT/TQ; 1 FT/NTQ; 1 PT/NTQ \\
\hline $95-96$ & 6 FT/TQ; 1 PT/TQ & 2 FT/TQ; 1 FT/NTQ; 2 PT /NTQ \\
\hline $96-97$ & 6 FT/TQ & 2 FT/TQ; 1 FT/NTQ; 2 PT/NTQ \\
\hline $97-98$ & $6 \mathrm{FT} / \mathrm{TQ}$ & 2 FT/TQ; 1 FT/NTQ; 4 PT/NTQ \\
\hline $98-99$ & $6 \mathrm{FT} / \mathrm{TQ}$ & 2 FT/TQ; 1 FT/NTQ; 5 PT/NTQ \\
\hline $99-00$ & 6 FT/TQ; 1 PT/TQ & 3 FT/TQ; 1 FT/NTQ; 3 PT/NTQ \\
\hline $00-01$ & 6 FT/TQ; 1 PT/TQ & 2 FT/TQ; 1 FT/NTQ; 5 PT/NTQ \\
\hline $01-02$ & $6 \mathrm{FT} / \mathrm{TQ}$ & 2 FT/TQ; 1 FT/NTQ; 9 PT/NTQ \\
\hline $02-03$ & 7 FT/TQ & $4 \mathrm{FT} / \mathrm{TQ} ; 1 \mathrm{FT} / \mathrm{NTQ}$ \\
\hline $03-04$ & $7 \mathrm{FT} / \mathrm{TQ}$ & 4 FT/TQ; 1 FT/NTQ \\
\hline $04-05$ & $7 \mathrm{FT} / \mathrm{TQ}$ & $5 \mathrm{FT} / \mathrm{TQ}$ \\
\hline $05-06$ & $6 \mathrm{FT} / \mathrm{TQ}$ & $6 \mathrm{FT} / \mathrm{TQ}$ \\
\hline $06-07$ & 7 FT/TQ & $7 \mathrm{FT} / \mathrm{TQ}$ \\
\hline $07-08$ & 7 FT/TQ & 6 FT/TQ; 1 PT/TQ \\
\hline \multicolumn{3}{|c|}{ Legend } \\
\hline $\begin{array}{l}\mathrm{FT}=\text { full-time } \\
\mathrm{PT}=\text { part-time }\end{array}$ & \multicolumn{2}{|c|}{$\begin{array}{c}\mathrm{TQ}=\text { terminally qualified } \\
\mathrm{NTQ}=\text { not terminally qualified }\end{array}$} \\
\hline
\end{tabular}


Excellent teaching is each faculty member's primary responsibility. The department believes holding faculty to high professional standards, especially over the past five years, explains to a significant degree the extraordinary MFTB scores during that period. In addition, the past two department chairs have held annual retreats, prior to the beginning of the new school year, to explain and clarify standards and expectations, especially for new faculty.

At VMI, academic standards for students are very high. Instructors are expected to help students meet these standards without ever lowering them. Curving of final grades is rare, and grade rolls contain plenty of Ds and Fs. A grade of $\mathrm{C}$ is needed in all required courses; and, weaker students may repeat several of them in order to graduate. We believe allowing students to avoid these courses and transfer credits from other schools compromises our control of instructional quality and, thus, does not accurately reflect our own teaching on the MFTB. For several years prior to 2002, students having difficulty in required EC-BU courses could drop them after the first exam and apply to retake them at another (perhaps easier) school. That lax transfer credit policy was tightened in 2002, in response to poor test results and with the arrival of a new department head.

Economics and Business is one of the most popular majors at VMI. Many introductory courses have been taught by multiple instructors. In the wake of the "Crash of 2002", a senior faculty member is now appointed as coordinator for multiple section courses to insure adequacy of topical coverage and consistent rigor. This is especially true when an adjunct instructor is utilized in a required course. In those rare instances, adjuncts receive additional guidance and scrutiny from their coordinator.

\section{CONCLUSIONS \& RECOMMENDATIONS}

Singularly, the changes described above may appear subtle and unspectacular. But, in the aggregate, they begin to explain the recent MFTB score for the EC-BU Department. In this section, we will more fully detail the perspectives, practices and policies developed over our fifteen years of experience with the test.

\section{Self Knowledge Is Essential}

When interpreting MFTB results, it is important to recognize the uniqueness of your school, students and/or curriculum. Highly selective vs. open admissions, public vs. private funding, traditional vs. non-traditional students or a quantitatively focused curriculum may be relevant factors, which alone or combined could contribute to or confound test results. For instance, Bycio and Allen (2007) found SAT scores and majors in accounting and finance, possible surrogates for selective admissions and a quantitative curriculum, were associated with higher MFTB scores. On the other hand, a public institution, with a significant number of serious and motivated nontraditional students, might find them underrepresented on a voluntary test that conflicted with their family obligations. Or, conversely, perhaps they would be the ones most likely to show up for the test.

VMI's unique military nature was mentioned earlier. In addition, most classes have a faculty to student ratio in the 15:1 range. Part-time students are not allowed, and cadets have 10 semesters to meet graduation requirements. A VMI student may take no more than 18 credits (out of 139) during summer sessions at other schools and cannot resign and still receive her/his degree with more than 10 credits outstanding. The EC-BU curriculum is tightly structured, with strict prerequisites. Given the grading standards mentioned above, it is not unusual to have students retake their accounting, finance, economics and quantitative courses at least once, often during VMI summer sessions. Our weakest students may attend classes 11 months per year (i.e., late August through late July). That the VMI educational experience is compressed, regimented, rigorous and intimate goes far in explaining our MFTB results over the past 5 years.

\section{Administration Matters}

To assert that test administration leads to higher scores would be both illogical and incorrect. We view administrative procedures as similar to experimental conditions, which can introduce or eliminate biases and 
contaminating factors. Our consistent test administration over the past 5 years allows us to examine all other explanations for test scores that have remained above the $90^{\text {th }}$ percentile for institutions.

After 2002, the department settled on a set of strict guidelines. We decided that the MFTB will not be given in the summer or fall semesters and that all graduating seniors will take the test together during the spring semester in the Business Policy capstone course. A two-hour block of time is set aside during an evening early in the semester, which substitutes for two regularly scheduled classes. For the past 5 years, the same instructor has administered the test in the exact, same manner each year, even with regard to the classrooms used and the time of day. We do not now nor have we ever "taught to the test". Cadets are provided no special preparation for the exam, with the exception of ETS' own set of instructions and sample test questions. They are urged to review old texts and class notes; and, the department makes available earlier editions of course texts in its library.

\section{Consistency Of Philosophy}

Education does not simply occur by "osmosis", when educators, students and teaching materials (e.g., texts, cases, videos) are together in the same room. Interpersonal and organizational factors are also at work. Teachers vary in their talent, preparation and enthusiasm. Schools vary in their emphasis on consistency and quality control. Those of us who have chosen education as a career have spent many years on "both sides of the desk" and have likely experienced wide variances in instructional quality, perhaps at the same school.

VMI and the EC-BU Department have high and uncompromising standards for teaching. They are explicit in the statement of faculty expectations and constitute the most significant category (of four) in annual faculty evaluations.

New faculty are assigned tenured colleagues as mentors, who work with them during their first year and beyond, providing insights and corrections as necessary. Teaching is evaluated from a multi-dimensional perspective, including but not limited to student questionnaires. Tenured and untenured faculty members are subject to the same strict scrutiny. In fact, standards rise consistent with experience.

The MFTB occupies a place of paramount importance among departmental activities, because it is viewed as an indicator of teaching effectiveness. Test scores across time figure prominently in departmental literature and presentations. They are examined at semi-annual meetings of our Business and Cadet Advisory Councils. The

EC-BU department head also meets with majors from each class once per semester. (This was not always the case, especially for several years prior to 2002.) It is a rare meeting when the importance of the MFTB and recent high scores are not mentioned. It is also important to note that the VMI administration supports the use of the test and subsidizes its annual cost.

\section{A 360 Degree View Of Problems (Low Scores)}

Do not make excuses, "point the finger of blame" or jump to hasty conclusions. It is essential to cure the disease rather than its symptoms. Potential questions include: (1) Is course coverage sufficient? (2) Are texts providing adequate topical coverage? (3) Are instructors teaching thoroughly and rigorously? (4) Are adjuncts or new faculty's expectations consistent with departmental standards? (5) Have regular semester student grades in the area(s) of concern been fluctuating wildly? (6) Are freshman SAT/ACT scores lower? (7) Is student motivation an issue?

The importance of student motivation in taking the exam is not only emphasized by Bycio and Allen (2007) but also reflects our own experience. We believe the "Crash of 2002" was brought on, in large measure, by low motivation born of inconsistent administration. Despite standing policies, the MFTB was worth only $10 \%$ of the Business Policy final grade that year, and the instructor promised no one would score lower than a $\mathrm{C}$, having been convinced by student complaints that it was impossible to truly "study" for the test. Some students sought high scores; others filled in their answer sheets with interesting patterns and left early. The department has now reaffirmed that the MFTB will always count at least $20 \%$ of the final grade in Business Policy. Cadets are clearly informed of the grading scale utilized and that it is possible to fail the test and perhaps receive a grade lower than a 
$\mathrm{C}$ in the course. A grade of $\mathrm{C}$ or higher is required for graduation; so, this represents a significant incentive for cadets to do their very best on the test.

\section{Do Not Panic}

Be sure administrators and faculty understand the structure of the MFTB and nature of the scores received. Individual subject areas average fifteen questions each. Accounting has the most. Some questions are doublecounted, which can be a blessing or a curse (e.g., economics and international; economics and finance). An institution's mean percent correct determines its percentile score in a given area. The seemingly small difference between 7/15 and 9/15 correct, on average, can lead to huge percentile swings. And, when examining percentiles, we must be cognizant of the relativity of those comparisons. Our mean percent correct in a given area may have, in fact, improved. But, if other schools administering the test showed larger gains, our percentile score could actually drop. Therefore, it would seem prudent to track both mean percent correct and percentile scores, in order to compare internally and externally.

\section{The MFTB Is Necessary But Not Sufficient}

The MFTB is best used with other, more fine-grained measures of discipline-based knowledge and skills. Martell (2007) reported many schools are using course-imbedded assessments of student learning. That solves two problems of the MFTB. First, course-imbedded assessments solve the content validity issue mentioned earlier. They also provide more timely feedback.

Unfortunately, we discovered the MFTB to be a slow-moving assessment tool when used singularly. The test picks up a problem a year or two after it occurred and may yield evidence of a solution two or three years down the road. In total, we are looking at a three to five year "fix cycle". In the accounting example mentioned earlier, the problem occurred in fall 2003 and was identified almost immediately. However, the anticipated low MFTB score did not show up until spring 2006. The "fix" occurred in fall 2004 and was revealed in spring 2007. The lag effect could be longer, if the problem's cause was subtle rather than obvious. For instance, we concluded, in retrospect, that low accounting scores in 2002 and earlier coincided with the frequent use of adjunct instructors from 1997 through 2000.

\section{Indirect Assessment}

Surveys of graduating seniors, recent and mature alumni, and employers can yield valuable information and provide "balance" to the more direct means AACSB now encourages. Under the right circumstances, exit surveys of seniors can provide useful insights as to the strengths and weaknesses of a program. (Even the comments of the most disgruntled can be helpful...after proper sanitizing.) Alumni are able to reflect on their academic experience in the context of their professional careers. And, employers, in the final analysis, are the "customers" we seek to satisfy. Allow them to inform us of the knowledge and skills they value in our graduates. In sum, indirect assessments help to avoid the myopia which results from examining only your own "reflection".

VMI's Department of Economics and Business is very proud of its students' recent MFTB scores and its role in producing them. However, we learned one of complacency's harsh lessons in the aftermath of the "Crash of 2002". It is a terrible mistake to assume excellence, then to expect performance. There will always be room for improvement. For instance, in 2007, only 8 of the 51 VMI cadets (15.7 percent) taking the MFTB scored at or above the $90^{\text {th }}$ percentile. From 2003 through 2006, the average had been 23.8 percent. We would like to see the proportion grow year-to-year and will work toward that goal.

Finally, the pursuit off AACSB accreditation has fundamentally changed the way our department looks at the assessment of student learning and the MFTB's role therein. We realize the MFTB and various surveys are only a fraction of the comprehensive assessment program AACSB now mandates. Feedback from this test will undoubtedly remain valuable. However, the long-term, macro perspective it provides is most effectively coupled with the micro analysis of course-imbedded measurements of knowledge and skills. 


\section{REFERENCES}

1. Allen, J. and Bycio, P. (1997). An Evaluation of the Educational Testing Service Major Field Test in Business. Journal of Accounting Education, 15, 503-514.

2. Black, T. and Duhon, D. (2003). Evaluating and Improving Student Achievement in Business Programs: The Effective Use of Standardized Assessment Tests. Journal of Education for Business, 79(2), 90-98.

3. Bycio, P. and Allen, J. (2007). Factors Associated with Performance on the Educational Testing Service (ETS) Major Field Achievement Test in Business (MFAT-B). Journal of Education for Business, 82(4), 196-201.

4. Chamberlain, D., and Seay, R. (1990). Outcomes Assessment: A New Challenge for Business Educators, Journal of Education for Business, 64(2) 202-205.

5. DeMong, R., Lindgren, J. and Perry, S. (1994). Designing an Assessment Program in Accounting, Issues in Accounting Education, 9,11-27.

6. $\quad$ Educational Testing Service. (2006). Major Field Tests: Comparative Data Guide. Princeton, NJ.

7. Johnson, R., McCormick, R. Prus, J., and Rogers, J. (1993). Assessment Options for the College Major. In T. Banta (Ed.), Making a Difference: Outcomes of a Decade of Assessment in Higher Education (pp.151-167). San Francisco: Jossey-Bass.

8. Martell, K. (2007). Assessing Student Learning: Are Business Schools Making the Grade?, Journal of Education for Business, 82(4), 189-195.

9. Mirchandani, D., Lynch, R., and Hamilton, D. (2001). Using the ETS Major Field Test in Business: Implications for Assessment, Journal of Education for Business, 77(1), 51-56.

10. Payne, S., Whitfield, J., and Flynn, J. (2002). Assessing the Business Capstone Course Through a Method Based on the SOTL and the Stakeholder Process, Journal of Education for Business, 78(2), 69-74.

11. Poje, D. (1996). Student Motivation and Standardized Testing for Institutional Assessment. In T. Banta (Ed.), Assessment in Practice: Putting Principles to Work on College Campuses_(pp.179-181). San Francisco: Jossey-Bass.

12. Pringle, C. and Mitri, M. (2007). Assessment Practices in AACSB-Accredited Business Schools, Journal of Education for Business, 82(4), 202-211.

13. Rudolph, L. (1996). Looking Beneath Standardized Test Scores. In T. Banta (Ed.), Assessment in Practice: Putting Principles to Work on College Campuses_(pp.179-181). San Francisco: Jossey-Bass. 


\section{APPENDIX A: Graphical Representations Of MFTB Acores By Disciplines}
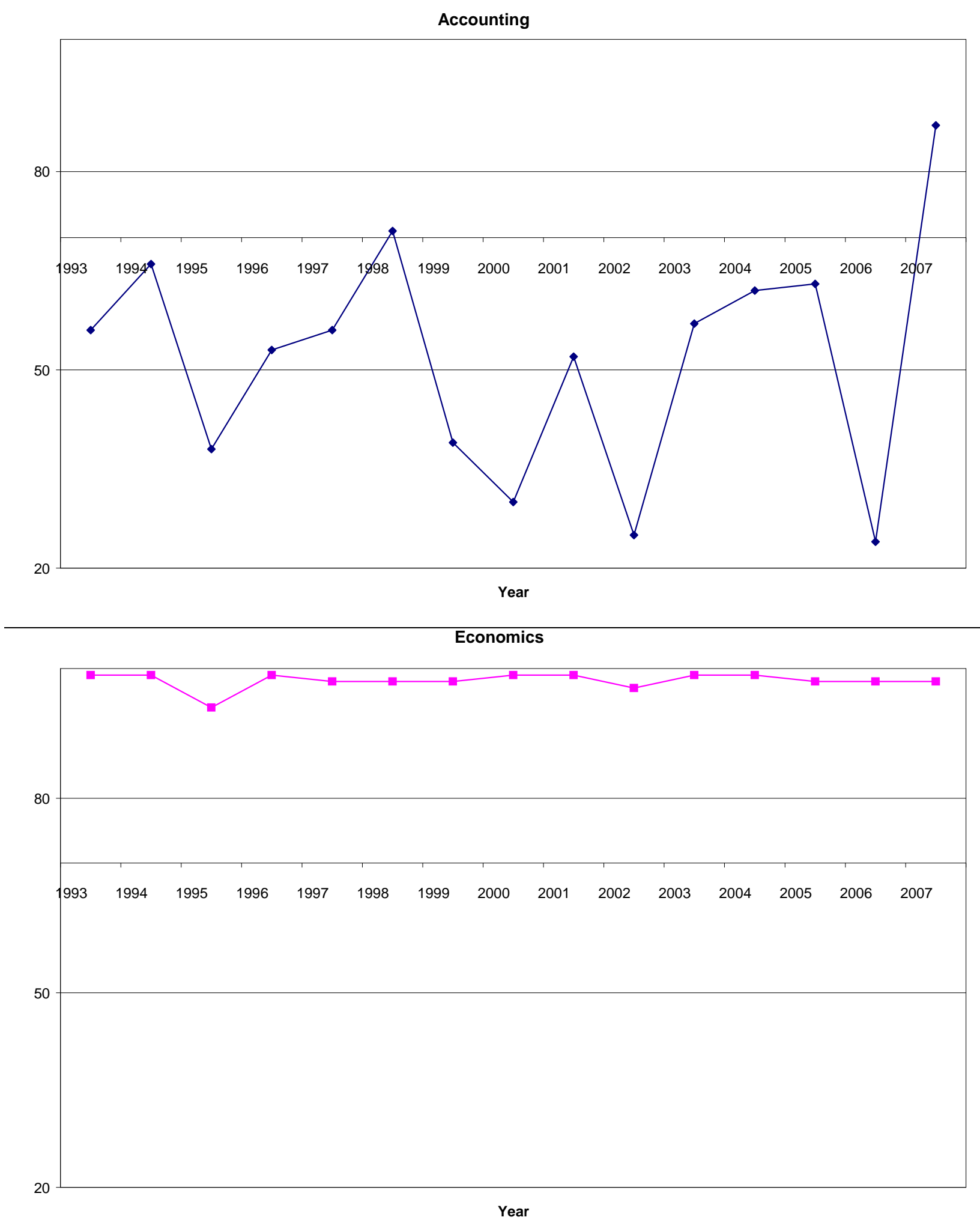
Finance

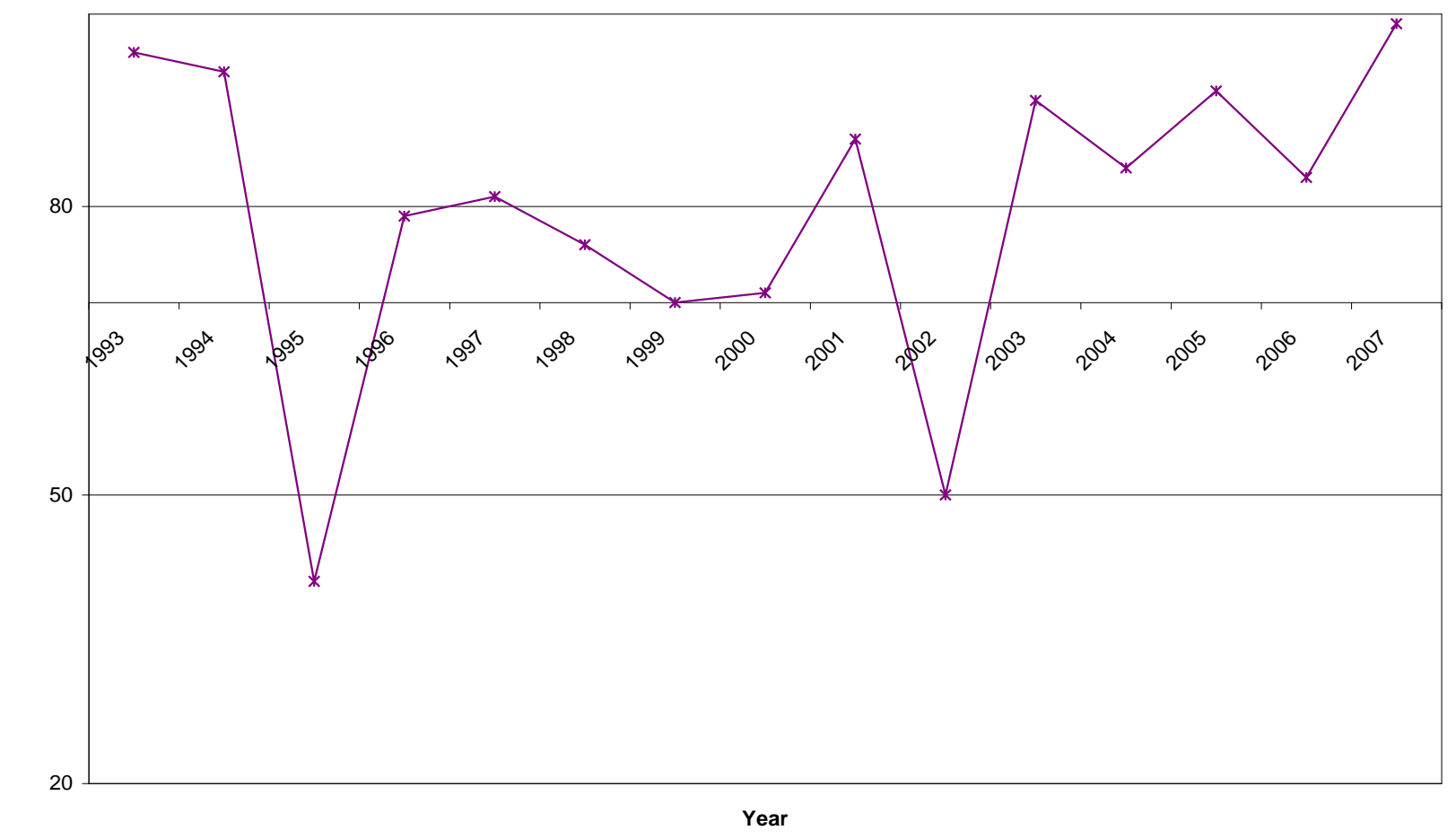

International

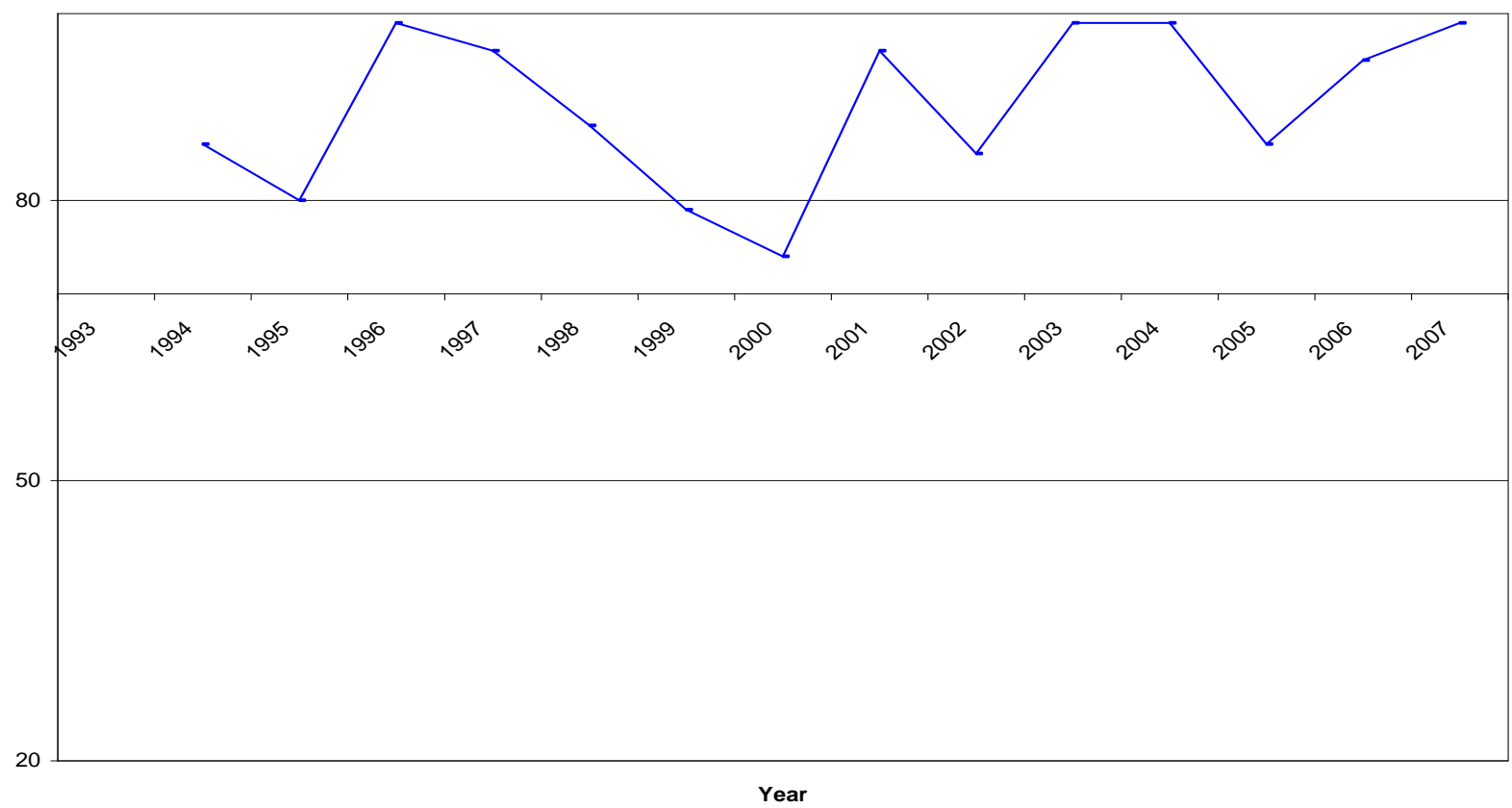



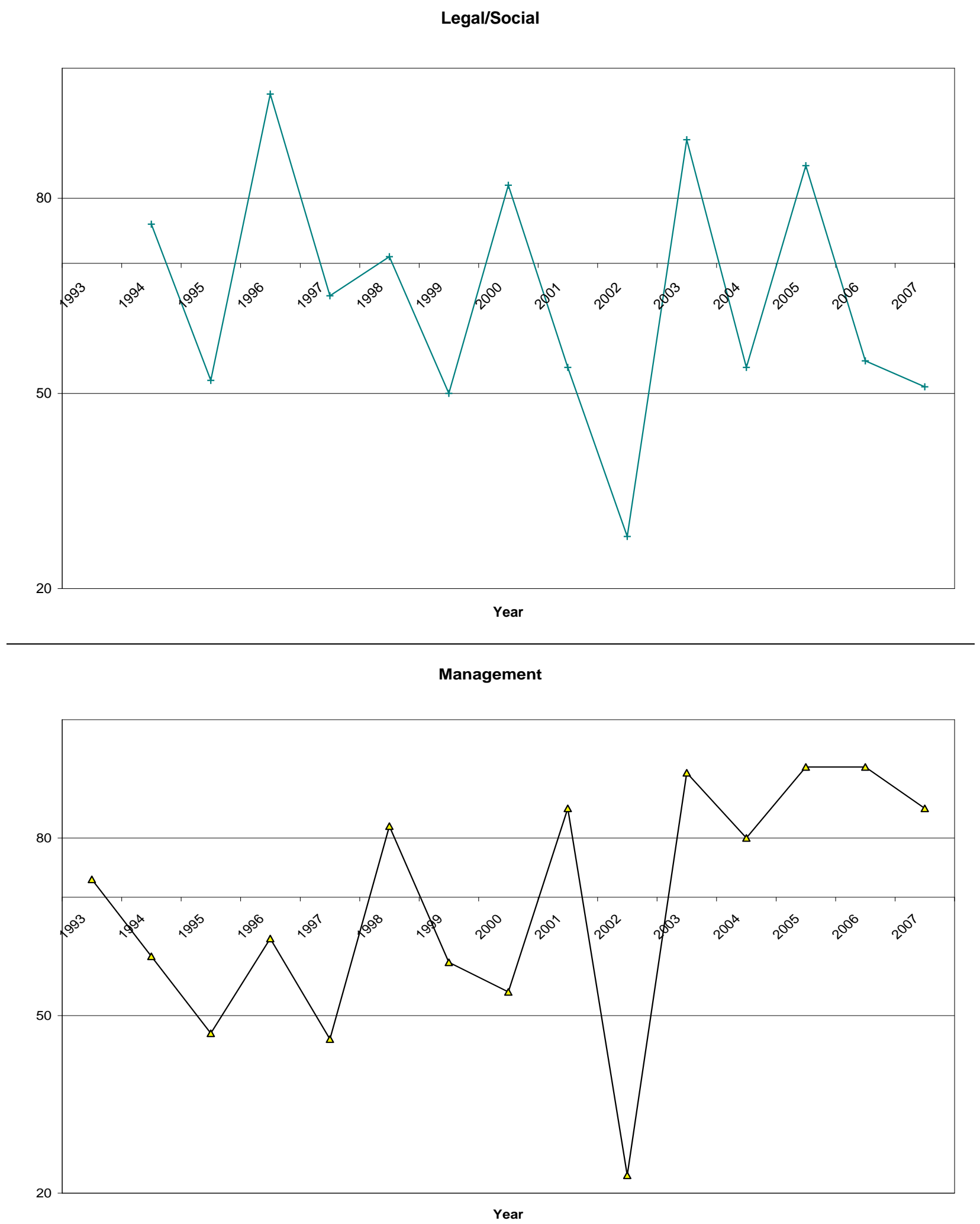


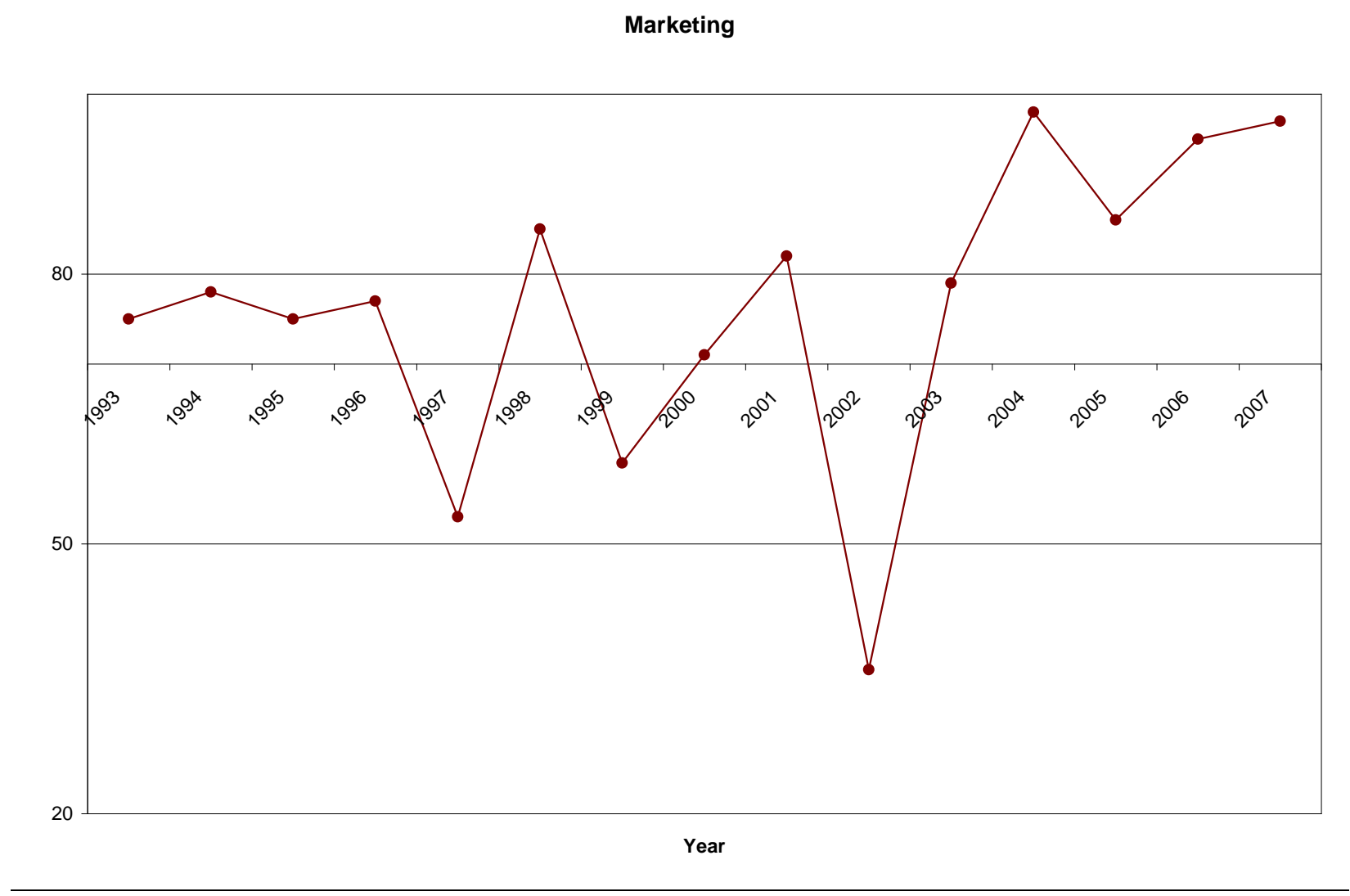

Quantitative Methods

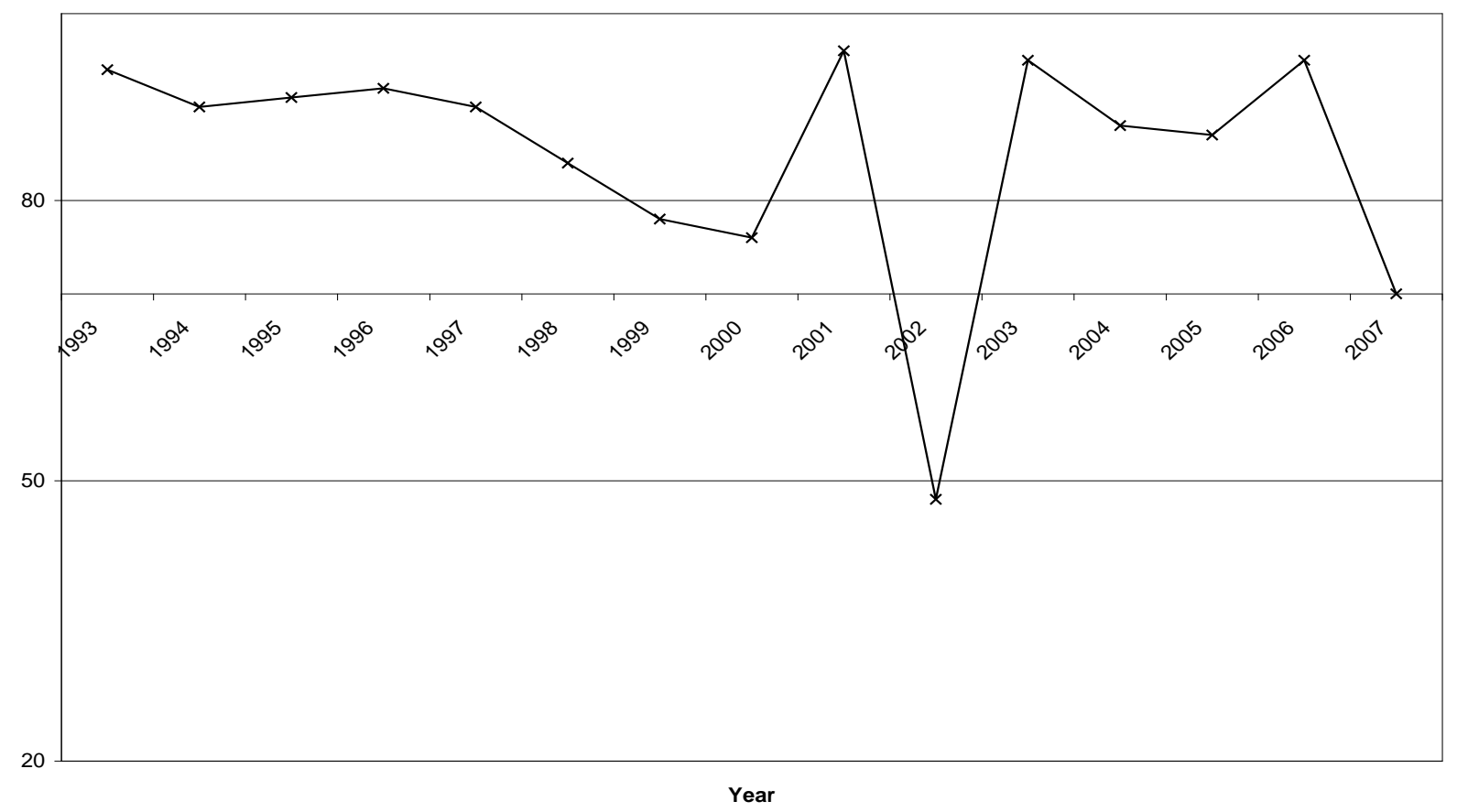

